This item was submitted to Loughborough's Research Repository by the author.

Items in Figshare are protected by copyright, with all rights reserved, unless otherwise indicated.

\title{
Modeling of the power cycling performance of a Si on Si flip chip assembly
}

PLEASE CITE THE PUBLISHED VERSION

PUBLISHER

(C) IEEE

VERSION

VoR (Version of Record)

LICENCE

CC BY-NC-ND 4.0

\section{REPOSITORY RECORD}

Ochana, Andrew R., David A. Hutt, David C. Whalley, Farhad Sarvar, and A. Al-Habaibeh. 2019. "Modeling of the Power Cycling Performance of a Si on Si Flip Chip Assembly". figshare. https://hdl.handle.net/2134/4218. 
This item was submitted to Loughborough's Institutional Repository (https://dspace.lboro.ac.uk/) by the author and is made available under the following Creative Commons Licence conditions.

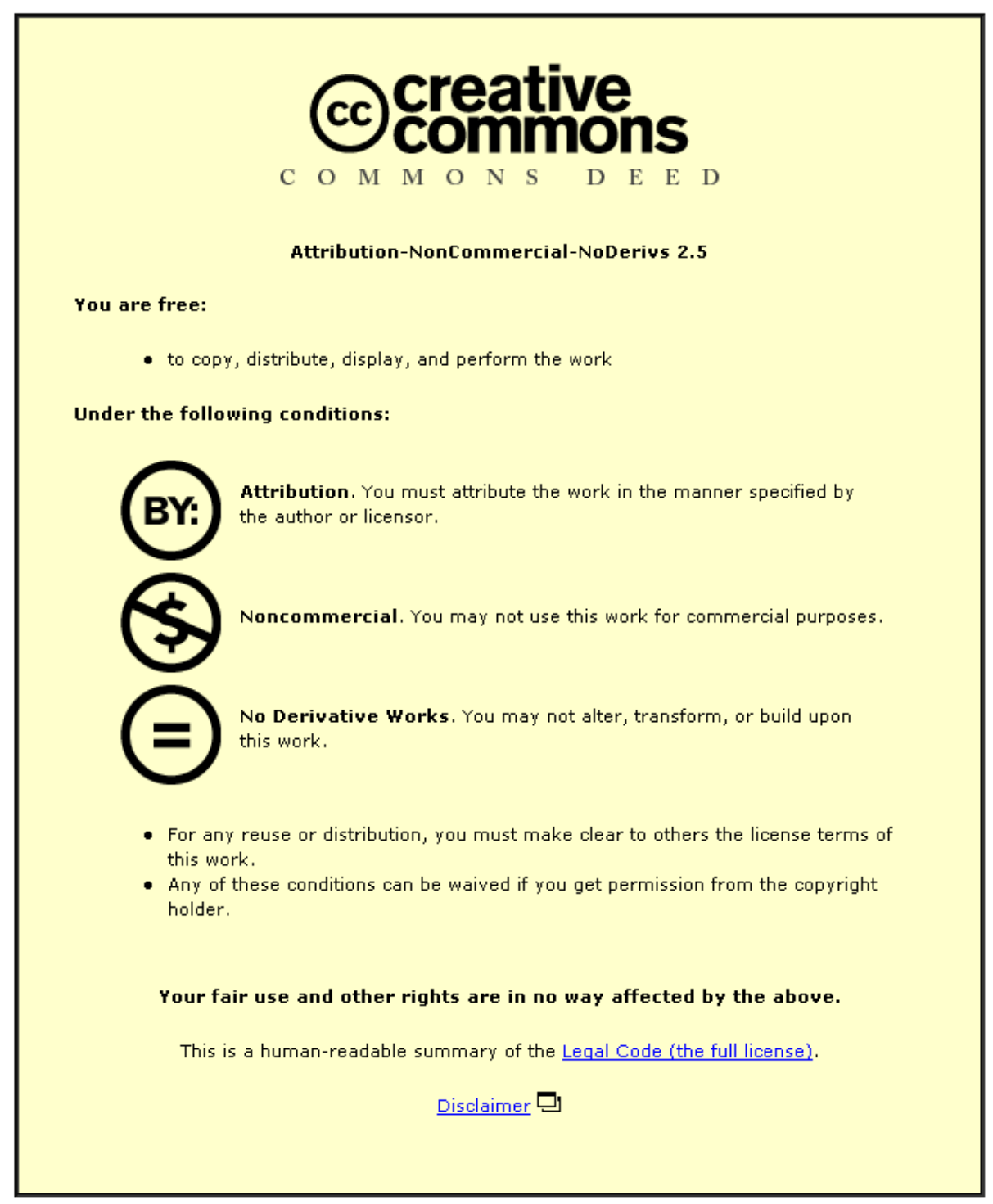

For the full text of this licence, please go to: http://creativecommons.org/licenses/by-nc-nd/2.5/ 


\title{
MODELING OF THE POWER CYCLING PERFORMANCE OF A Si ON Si FLIP CHIP ASSEMBLY
}

\author{
A.R. Ochana ${ }^{1}$, D.A. Hutt ${ }^{1}$, D.C. Whalley ${ }^{1}$, F.Sarvar ${ }^{1}$ and A. Al-Habaibeh ${ }^{2}$ \\ ${ }^{1}$ Wolfson School of Mechanical and Manufacturing Engineering \\ Loughborough University \\ Loughborough \\ Leicestershire, LE11 3TU, UK \\ ${ }^{2}$ Advanced Design and Manufacturing Engineering Centre-ADMEC \\ School of the Built Environment, \\ The Nottingham Trent University, \\ Nottingham, NG1 4BU, UK \\ Email: $\underline{\text { A.R.Ochana@,1boro.ac.uk }}$
}

\begin{abstract}
Flip Chip (FC) technology offers many advantages over conventional surface mount technology, including a smaller device footprint and higher interconnection density. Low power but complex consumer items, such as mobile telecommunications devices, utilise this packaging technology and it is likely to spread to other electronics sectors where components have higher power dissipations and/or they have to operate in a hostile environment.
\end{abstract}

As the scope for FC packaging broadens, a reliable means of establishing the long term performance of a particular package is necessary. Traditionally thermal cycling has been a primary reliability test for electronic assemblies including FC, however this fails to capture the behaviour of assemblies where the component thermal expansion is well matched to that of the substrate due to the isothermal heating and cooling of the assembly. In this situation power cycling offers an alternative means of determining the module performance.

This paper describes the use of Finite Element Modeling (FEM) to explore the effects of power cycling on a silicon on silicon Multi-Chip Module (MCM) constructed with a low solder joint standoff height of $30-35 \mu \mathrm{m}$. Particular attention was given to the boundary conditions that are inevitably atypical of those used in traditional thermal cycling. The paper presents results of the temperature distributions throughout the assembly, which were found to depend upon the substrate base material (FR4 or copper) that the MCM was attached to. The results of the FEM analysis were verified by assembling test devices and measuring their temperature distribution under steady state and power cycling conditions. The predicted temperatures may then be used as boundary conditions in FEM of thermal stresses and fatigue in the assembly.

KEY WORDS: Flip Chip, Finite Element Analysis, Power Cycling, Multi-Chip Modules.

\section{INTRODUCTION}

Flip chip (FC) assembly is becoming a mainstream technology among electronics manufacturers, due to the many potential advantages over conventional surface mount technology including: a lower package profile, the potential to provide a much greater number of (area array) connections and shorter interconnection paths [1]. This packaging method is most obviously exploited in the mobile telecommunications sector where products are significantly smaller, yet far more sophisticated than their predecessors. $\mathrm{FC}$ is increasingly being implemented in other electronics sectors where the performance and environmental requirements may be significantly more demanding, and/or where reliability is critical.

Although thermal cycling tests have been used for many years to establish the reliability of electronic devices, including FC assemblies [2,3], it fails to correctly capture the true thermal characteristics an assembly would be subjected to in an operational environment. The main issue regarding thermal cycling is that the heat is supplied from an external source, resulting in a near isothermal temperature distribution which is independent of the test-vehicle. In service, the assembly is more likely to experience an anisothermal temperature distribution due to a combination of variations in the temperature of the operating environment and local changes due to heat dissipation within the components. In the latter case, for components generating significant heat, the internal temperature may be much greater than that of the substrate [4-6]. Furthermore, thermal cycling typically imposes temperature ramp rates that are quite slow compared to the rate at which an assembly heats up due to internal power generation. Power cycling will therefore better capture the transient nature of a component heating up or cooling down, which may have significant reliability implications. When traditional organic substrates are used, monitoring of the transient behaviour of FC devices has revealed that the joints first endure shear stress in one direction as the die heats up rapidly, but then in the opposing direction due to the substrate heating up more slowly but with typically a 
significantly larger Coefficient of Thermal Expansion (CTE) $[5,6]$. In a $\mathrm{Si}$ on $\mathrm{Si}$ assembly the uniform temperatures within the device during thermal cycling may result in minimal stresses due to the matched CTEs, however, depending on its duty cycle, the chip is likely to endure a greater and more rapid temperature change than the substrate [4].

To address the issues raised above, power cycling tests can be used to simulate the more realistic situation of heat generated by the components. Power cycling involves switching the power dissipation in the assemblies between two levels, typically zero and maximum power, for specific durations. As such, the equipment for testing can be more straightforward than for thermal cycling. Furthermore, an additional advantage of power cycling is the reduced time taken to complete a cycle, which may be as short as one minute [7].

While providing a high level of confidence in any given assembly's performance, the procedure of manufacturing test vehicles and performing subsequent power cycle trials is costly with respect to time (trials may take months to complete) and resources (many assemblies need to be produced and are of little further use after testing). In an attempt to reduce such costs, computer modelling methods are increasingly used for the simulation of thermal/power cycling. This paper describes the development of a finite element model (FEM) to represent the power cycling of a silicon on silicon flip-chip assembly attached to either a copper or FR4 substrate. The aim was to examine how the temperature distribution within the device varied as a function of power input, time and substrate material thermal conductivity.

\section{EXPERIMENTAL PROCEDURE \\ MCM Test Vehicle Assembly}

The test vehicle studied consisted of a silicon "heater" chip mounted on a silicon "carrier" chip, which itself was attached to a substrate that was either FR4 or copper. Figure 1 shows a schematic diagram of a test vehicle mounted on a substrate. The heater chip and carrier chip are shown in figures $2 \mathrm{a}$ and b respectively. The heater chip was a $3 \mathrm{~mm} \times 3 \mathrm{~mm} \times 0.5 \mathrm{~mm}$ silicon die that bore a large central resistive element (the heater), two aluminium tracks to allow chip temperature measurement via four point resistance measurements, and tracks between pairs of bond pads that formed half of a "daisy chain" interconnection pattern. The carrier chip was also a silicon die, but was larger at $6 \mathrm{~mm} \times 6 \mathrm{~mm} \times 0.5 \mathrm{~mm}$, and included a series of larger pads for the external connections as well as the corresponding pads to match those on the heater chip.

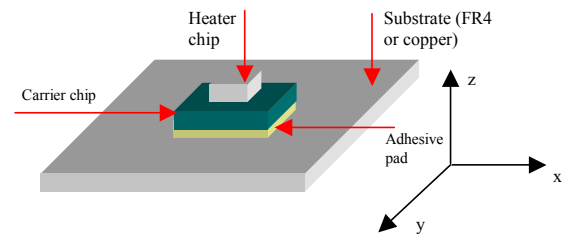

Fig. 1 Schematic view of Si on Si MCM mounted on substrate
The aluminium bond pads for flip-chip connection were $3 \mu \mathrm{m}$ thick and had circular openings in the passivation approximately $75 \mu \mathrm{m}$ in diameter. Both chips had an UBM of electroless nickel applied (heater chip $15 \mu \mathrm{m}$, carrier chip $6 \mu \mathrm{m})$ and were $60 / 40 \mathrm{Sn} / \mathrm{Pb}$ solder bumped using a maskless dipping process similar to that described in [8]. The bumped die were assembled by applying fluxes and reflowing: no additional solder was added such that a small standoff height of $30-35 \mu \mathrm{m}$ was achieved. A cross-section of a joint is shown in figure $2 \mathrm{c}$ where the bond-pad, UBM and solder are clearly identifiable. Underfill was not used in this study. The completed daisy chain interconnection was made up of a total of 36 joints arranged in a peripheral array $((2 \times 8)+(2 \times 10))$ at pitches of either $300 \mu \mathrm{m}$ or $225 \mu \mathrm{m}$. There were five different electrical paths: the heater, which was directly connected to the power supply, two separate daisy chains and two sets of connections to the temperature sensing tracks that allowed for 4-point resistance measurements to be taken.
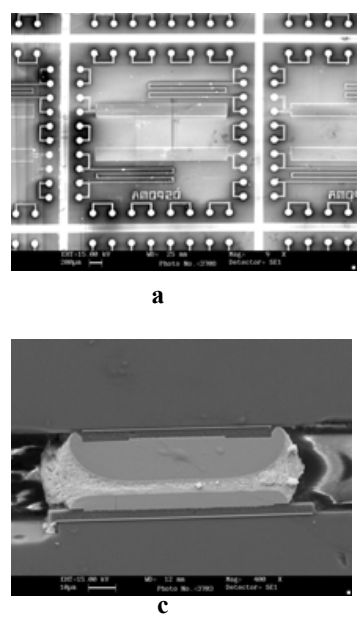

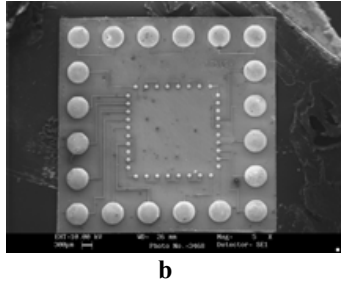

b

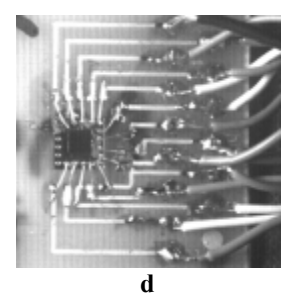

Fig. 2 a) SEM image of the heater chip, b) SEM image of the carrier chip after dicing and solder dipping, c) cross-section through a single solder joint between heater and carrier chip, d) completed test vehicle mounted on an FR4 substrate with connecting wires.

\section{Attachment of MCM to Substrate}

Two substrate types were used in this investigation: a glass reinforced epoxy laminate (FR4) and copper. These were chosen to represent the likely extremes of thermal conductivity of potential substrates for such components. The MCM was secured to the centre of the substrate using a Chomerics T404 thermally conductive adhesive pad. The FR4 substrate was $40 \mathrm{~mm} \times 40 \mathrm{~mm}$ x $0.8 \mathrm{~mm}$, with a $35 \mu \mathrm{m}$ thick copper pattern on one side only. Tracks to allow connections between the MCM and larger external connections were wet etched on the substrate using standard PCB manufacturing processes. Fine wires were then manually connected between the larger pads of the carrier chip and an array of corresponding pads on the substrate that enabled external connections to be made to the power supply and the test vehicle monitoring apparatus. A completed test vehicle is shown in figure $2 \mathrm{~d}$ where the MCM was mounted 
on a FR4 substrate. The copper substrates $(40 \mathrm{~mm} \times 40 \mathrm{~mm} x$ $1 \mathrm{~mm}$ ) were cut from copper sheet and were used to represent the MCM mounted on a highly thermally conductive substrate. $50 \mathrm{~mm}$ long insulated fine wires were first connected to the BGA pads on the MCM then larger wires were attached to the other ends to facilitate the connection to the power source.

\section{Wind Tunnel and Power Cycling Test Configuration}

To validate the thermal models it was necessary to test completed assemblies in a controlled environment. A simple wind tunnel as used in previous studies by the authors [9] allowed airflow rates up to $10 \mathrm{~m} / \mathrm{s}$ when sealed $(5 \mathrm{~m} / \mathrm{s}$ when open) and was used to house the test vehicles and provided a constant airflow for the required time period. A schematic of the wind tunnel is shown in figure 3, where the typical positioning of the test vehicle is also indicated.

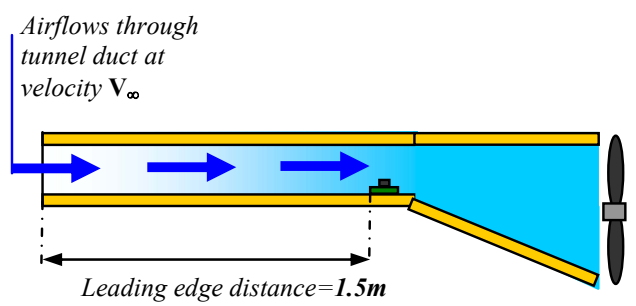

Fig. 3: Schematic view of the wind tunnel.

\section{Measurement of MCM Temperature Distribution}

The temperature distributions within the MCMs were evaluated using two different techniques. The first was to use four point resistance measurements of the long aluminium tracks on the heater chip. The variation in resistance with temperature was calibrated by placing test devices in an oven and recording the track resistance at a number of temperatures. Following this, it was possible to determine the temperature of the MCM in the vicinity of the heater from the resistance.

In addition, to the four point resistance measurements, two thermal imaging cameras were used to capture an overall thermal profile of the devices. There were high and low resolution cameras available. The high-resolution camera was a ThermaCAM ${ }^{\circledR}$ P40 thermal imager that produced still images with a resolution of $320 \times 240$ pixels. In order to use the high-resolution camera with no obstruction between it and the sample, it was necessary for the wind tunnel to be "open". This meant that a maximum airflow of only $5 \mathrm{~m} / \mathrm{s}$ was available and, as described later, created turbulence above the sample. The low-resolution camera was an IRISYS IR11002 imager with a resolution of $16 \times 16$ pixels over an area of $35.2 \mathrm{~mm} \times 35.2 \mathrm{~mm}$. This camera did not require the wind tunnel to be open and therefore a maximum airspeed of $10 \mathrm{~m} / \mathrm{s}$ was possible. Although a much lower resolution, this camera offered the additional benefit of being able to capture successive images such that a transient profile "movie" could be obtained. For the low-resolution camera, the test vehicle was carefully positioned with respect to the camera lens such that the pixels overlaid the relevant parts of the assembly, as shown in figure 4 . Therefore the resultant resolution would render the heater chip readily identifiable as the hottest pixel in the image and the surrounding pixels would indicate the carrier chip temperature. The pixels labelled a $\&$ b in figure 4 were considered to provide the best estimates of the carrier chip temperature given the low resolution.

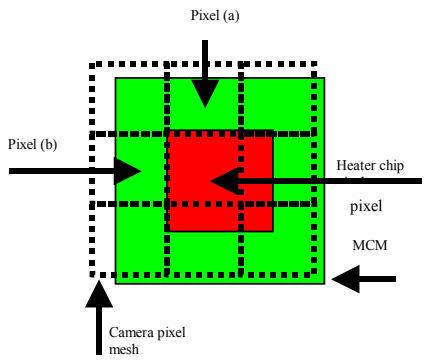

Fig.4 Pixel allocation for the low resolution thermal imaging camera.

\section{Finite Element Model Generation}

The Finite Element Pre and Post processor used MSC's MENTAT 2000, along with their MARC solver. A 3Dimensional model of the test vehicle was created. The symmetry of the assembly meant that the model could be simplified to $1 / 4$ of the assembled test vehicle, and the model utilised 15232 eight noded hexahedral "brick" elements. The model consisted of the silicon heater chip and carrier chip, the aluminium bond pads, the nickel UBM, solder, adhesive and the relevant substrate material. To simplify the domain, the BGA pads, all connecting wires, and the copper tracks on the substrate were omitted from the model. The material properties used are summarised in table 1. The thermal conductivity data for FR4 was sourced from [10] and the other materials properties were taken from www.matls.com.

Table 1. Material properties used in the FEA.

\begin{tabular}{|l|c|c|c|}
\hline Material & $\begin{array}{l}\text { Density } \\
\left(\mathbf{k g} / \mathbf{m}^{3}\right)\end{array}$ & $\begin{array}{l}\text { Thermal } \\
\text { Conductivity } \\
(\mathbf{W} / \mathbf{m} . \mathbf{K})\end{array}$ & $\begin{array}{l}\text { Heat } \\
\text { Capacity } \\
\text { (J/kg.C) }\end{array}$ \\
\hline Silicon & 2330 & 124 & 702 \\
\hline SnPb Solder (60/40) & 8600 & 49.8 & 173 \\
\hline Aluminium & 2699 & 210 & 900 \\
\hline Nickel & 8880 & 60.7 & 460 \\
\hline Adhesive & 1420 & 0.37 & 109 \\
\hline Copper & 8960 & 385 & 385 \\
\hline FR4 & 2540 & $1.0(\mathrm{X} \& \mathrm{Y}) 0.3(\mathrm{Z})$ & 810 \\
\hline
\end{tabular}

The characteristics of the assembly were such that the areas of interest (interconnection joints) were comparatively small with respect to the overall geometry. Models with sufficient mesh density in these areas, but with no refinement elsewhere, were considered but resulted in an unacceptably large number of elements, leading to prohibitive analysis durations. Therefore considerable effort was made to refine the mesh, such that the mesh was dense around the area of the interconnection joints, whilst a coarse mesh was used around the chip, substrate and board. Figure 5 shows the mesh refinement used. 
Boundary Conditions: Heat generation

A face flux was applied over the area of the chip where the heater was situated. As the work was not concerned with time dependent mechanical behaviour, such as creep, it was considered beneficial to keep the cycle time as short as possible. After a number of initial simulations, a complete cycle time of 128 seconds (64s on / 64s off) was found to be an adequate time period for the assembly to approach steady state when mounted on a FR4 substrate. For $10 \mathrm{~m} / \mathrm{s}$ airflow, a temperature change of $63.4^{\circ} \mathrm{C}$ was recorded in the heater chip after this time period compared with a steady state temperature change of $63.8^{\circ} \mathrm{C}$.

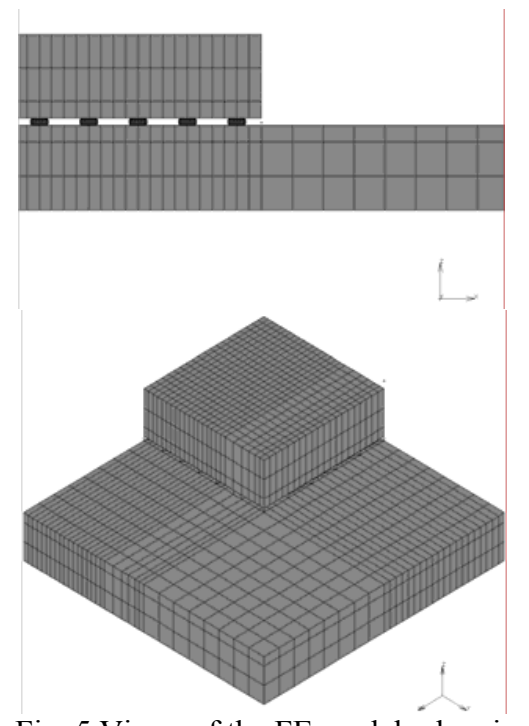

Fig. 5 Views of the FE models showing the mesh refinement.

\section{Boundary Conditions: Convection heat transfer}

In the test environment of the wind tunnel little heat was lost through conduction from the substrate into the tunnel platform, due to the low conductivity of the tunnel material, and most heat was lost through forced convection from the other surfaces of the assembly to the surrounding airflow. The application of the convection heat transfer boundary conditions was given detailed consideration to ensure it provided an adequate representation of the true environmental conditions the test vehicle was subjected to. The FE model simulated power cycling of the test vehicle mounted inside the wind tunnel subjected to a constant air velocity of 5 or $10 \mathrm{~m} / \mathrm{s}$ at $20^{\circ} \mathrm{C}$.

It was assumed that the airflow across each body was equivalent to that over a flat plate (i.e. the MCM height was neglected) and, based on calculations of the Reynolds number, the flow was assumed to be laminar (non turbulent). In addition, the airflow across the surface was considered to be external convection. Different methods of determining the convection heat transfer " $h$ " coefficients were investigated, including treating the leading edge of the tunnel (including the test vehicle) as a single surface, and only considering the substrate as a convection surface (neglecting the MCM dimensions). The " $h$ " coefficients calculated using both these methods were tested in the model, but they resulted in over-estimates of the resultant assembly temperatures. Upon further investigation, it became apparent that the heights of the different components of the test vehicle were not insignificant in relation to the calculated height of the thermal or velocity boundary layer, therefore it was necessary to consider each component of the assembly individually. The assembly was therefore divided into three bodies: the heater, the carrier and the substrate; and a " $h$ " coefficient applied separately for each. The average values over the surfaces of interest were derived by utilising equations and formulae from [11] and were obtained for airflow rates of 5 and $10 \mathrm{~m} / \mathrm{s}$ and are listed in table 2 with their corresponding allocation in figure 6 .

Table 2. Convection coefficients (“ $h$ ”) used.

\begin{tabular}{|l|c|c|}
\hline \multirow{2}{*}{} & \multicolumn{2}{|c|}{ Convection coefficients $\left(\mathbf{W} / \mathbf{m}^{\mathbf{2}} . \mathbf{K}\right)$} \\
\cline { 2 - 3 } & $\mathbf{5} \mathbf{~} / \mathbf{s}$ airflow & $\mathbf{1 0 ~} \mathbf{~} / \mathbf{s}$ airflow \\
\hline Heater, $h_{3}$ & 160 & 230 \\
\hline Carrier, $h_{2}$ & 113 & 160 \\
\hline Substrate, $h_{1}$ & 43.7 & 61.9 \\
\hline
\end{tabular}

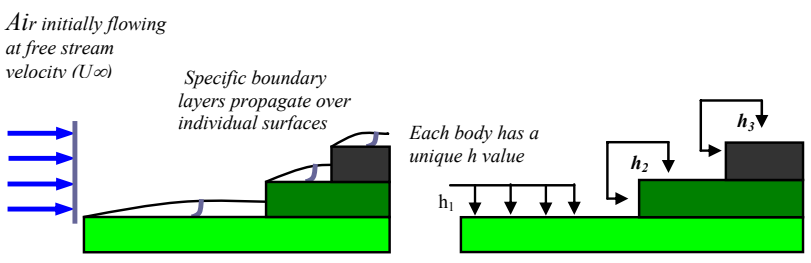

Fig. 6 Allocation of individual convection coefficients as used in the model.

\section{Boundary Conditions: Mechanical constraints}

Symmetric boundary conditions typically used when modelling $1 / 4$ of a domain were implemented. All nodes along the $\mathrm{x}$ and $\mathrm{y}$ axis symmetry planes were constrained in the orientation normal to their respective axis. In addition, a single node was constrained in the $\mathrm{z}$ direction to prevent free body motion.

\section{Steady State Thermal Models}

A steady state analysis to obtain the maximum temperature for the MCM was first performed with an input power level to the heater of $1.2 \mathrm{~W}$ and an airflow of $5 \mathrm{~m} / \mathrm{s}$ for both FR4 or copper substrates. Figures $7 \mathrm{a} \& \mathrm{~b}$ show the steady state thermal plots obtained for an assembly mounted on a FR4 substrate. The heater chip exhibited a temperature rise of $80^{\circ} \mathrm{C}$, while the carrier chip temperature rise was $74^{\circ} \mathrm{C}$. It can be seen that for the heater and carrier chips, there is a very small temperature gradient over both bodies, with both profiles showing temperature variations of less than $1.5^{\circ} \mathrm{C}$. A clear temperature gradient could be seen across the solder joints, which was attributed to the comparatively poor thermal conductivity of solder (compared with silicon) and their small cross-sectional area. The substrate temperature in the vicinity of the MCM was found to increase significantly, while the peripheral areas showed no temperature change. 

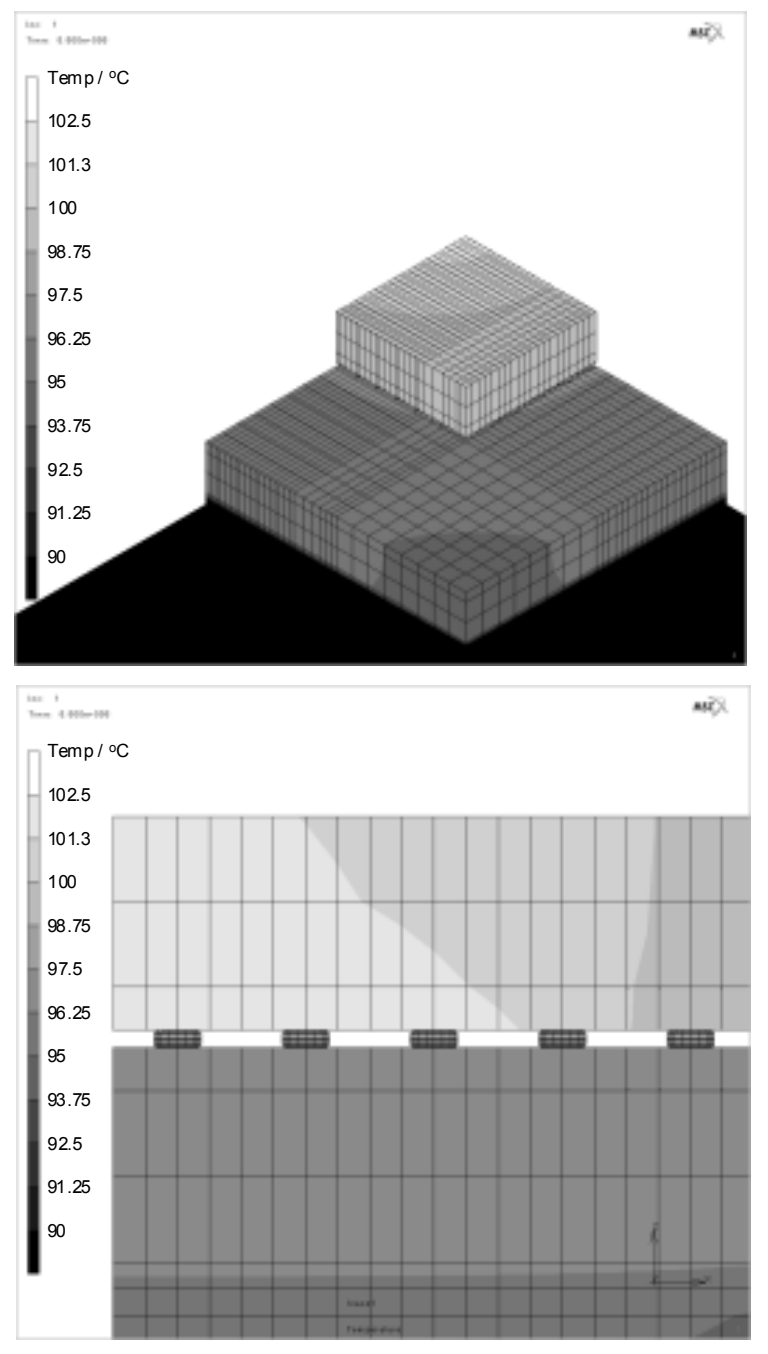

Fig. 7 Steady state model results of the MCM on FR4 (1.2 $\mathrm{W}$ power input, $5 \mathrm{~m} / \mathrm{s}$ airflow). a) Isometric view, b) side view of the model taken from the $\mathrm{x}$-axis.

For samples with a copper substrate (figure 8), a similar temperature distribution was observed within the heater and carrier chip, however the maximum temperature changes were only $26^{\circ} \mathrm{C}$ and $20^{\circ} \mathrm{C}$ respectively. In contrast to the FR4, the copper substrate showed a uniform temperature across the surface (i.e. areas close to the MCM exhibited the same temperature as the area near the edge), as would be expected considering the very high thermal conductivity of copper.

\section{Validation of steady state thermal models}

The MCM test vehicles were mounted in the wind tunnel and the power input and airflow rates were set such that they matched the boundary conditions for the FE models. Steady state was determined when the temperature measured using the aluminium track showed no more than a $0.045^{\circ} \mathrm{C} / \mathrm{min}$ change. Once the assembly had reached steady state then a thermal image was taken.

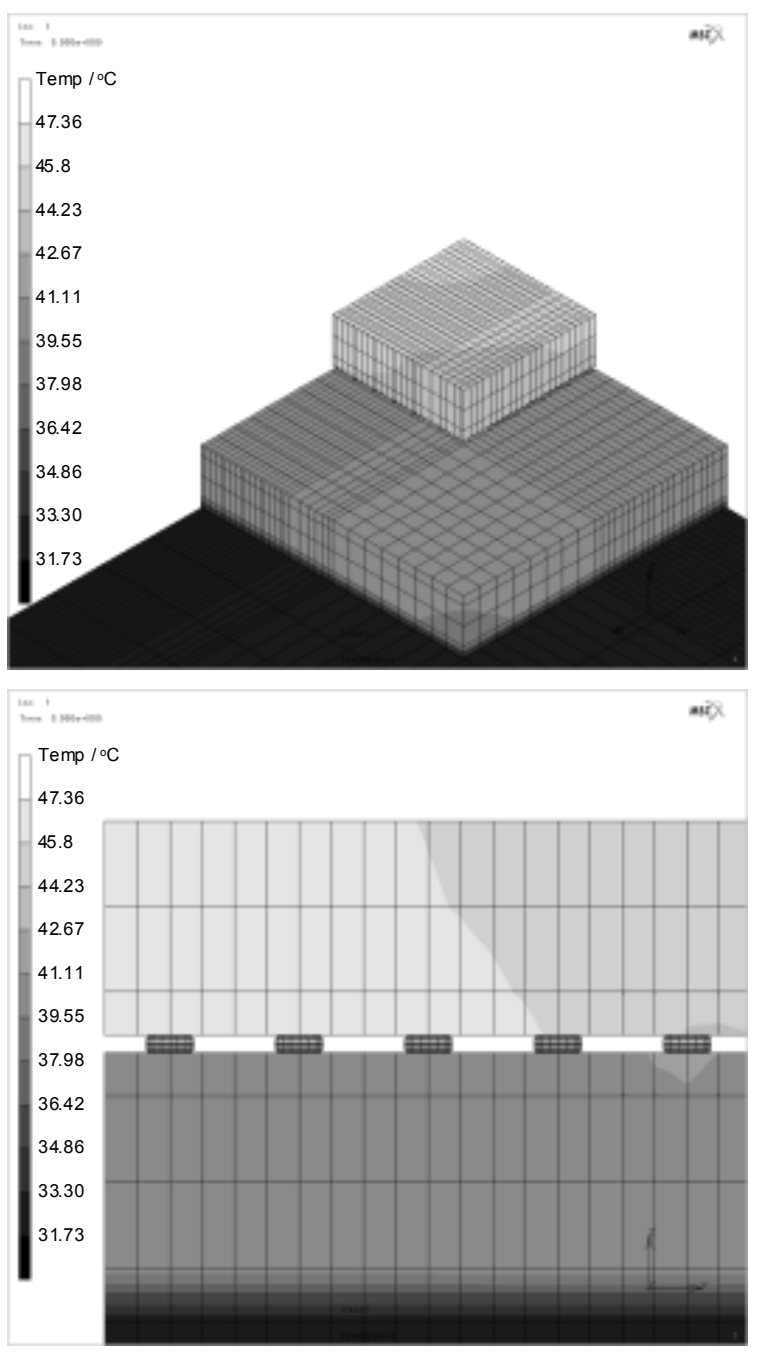

Fig. 8 Steady state model results of the MCM on copper (1.2 W power input, $5 \mathrm{~m} / \mathrm{s}$ airflow). a) Isometric view, b) side view of the model taken from the $\mathrm{x}$-axis

Figure 9a shows the thermal profile of the test vehicle on FR4 captured using the high resolution camera. A power level of $1.2 \mathrm{~W}$ was applied to the heater and an airflow of $5 \mathrm{~m} / \mathrm{s}$ was used to cool the sample. A maximum temperature change of $88^{\circ} \mathrm{C}$ was observed for the heater chip, which correlated well with the four-point resistance measurements that indicated a temperature rise of $90^{\circ} \mathrm{C}$. These results were in reasonable agreement with the $\mathrm{FE}$ analysis that showed an $80^{\circ} \mathrm{C}$ change. The carrier chip showed an approximately $80^{\circ} \mathrm{C}$ change, which was also somewhat higher than the $74^{\circ} \mathrm{C}$ of the FE model. The discrepancy between the experimental results and the model was thought to be due to the opening in the wind tunnel, that was necessary to allow an uninterrupted view of the samples by the high resolution camera and which would disrupt the nominal $5 \mathrm{~m} / \mathrm{s}$ airflow. The tunnel was therefore sealed and a measurement of the four point resistance alone made. This was found to indicate a temperature rise of $80^{\circ} \mathrm{C}$, which was in excellent agreement with the thermal model. For subsequent imaging the low 
resolution camera was employed, allowing the wind tunnel to be sealed during measurements.

From the thermal images it was evident that the FR4 substrate became warm in the area close to the MCM, but no temperature change could be seen further from the substrate, which was also in agreement with the simulation. However, it was noted that the temperature distribution was not symmetrical in the thermal image. Comparison with the device layout shown in figure $2 \mathrm{~d}$ showed that the copper tracks and wires used to connect the MCM to the board and to the external power supply were influencing the spread of heat. These were not included in the model, as this would have greatly increased the number of elements and would have invalidated the $1 / 4$ symmetry used as the copper tracks were not symmetrical.

Temperature measurements of the MCMs mounted on the copper substrate also showed good agreement with the models. The 4-point resistance measurements indicated a maximum temperature rise of $28^{\circ} \mathrm{C}$, while the thermal camera (figure 9b) showed the heater chip surface to rise by $27^{\circ} \mathrm{C}$ (compared with $26^{\circ} \mathrm{C}$ for the $\mathrm{FE}$ model) and the carrier chip to have a change of approximately $19^{\circ} \mathrm{C}\left(20^{\circ} \mathrm{C}\right.$ for the FE model).
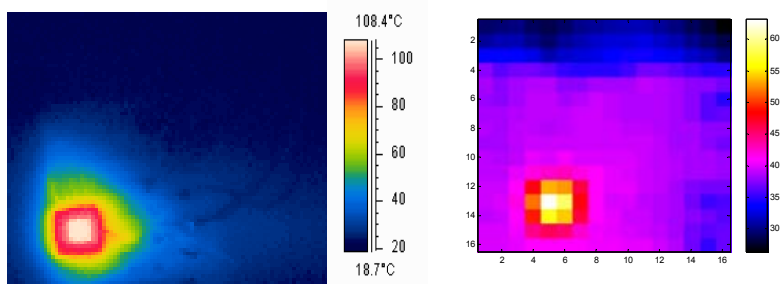

Fig. 9 Captured thermal images of the MCMs. a) FR4

substrate - image taken with high resolution camera, b)

copper substrate - image taken with low resolution camera.

\section{Transient Thermal Models}

As stated in the introduction, a flaw of traditional thermal cycling tests is that they fail to correctly reproduce the transient thermo-mechanical behaviour of an assembly when power is supplied. Therefore power cycling simulations were performed for the test vehicle on both FR4 and copper substrates. The MCMs were powered with $1.2 \mathrm{~W}$ and cooled with an airflow of $10 \mathrm{~m} / \mathrm{s}$. This greater airflow could only be achieved once the wind tunnel was sealed. The simulation was run for three complete power cycles, each with the power on for $64 \mathrm{~s}$ and then off for $64 \mathrm{~s}$. The FE models used 300 time increments, therefore each increment represented $1.28 \mathrm{~s}$ (adaptive increments were not used in this analysis).

To monitor the temperature changes occurring during the power cycling, the same three nodes were chosen in all models: one on the heater chip (a); one on the carrier chip (b); and one on the substrate close to the MCM (c). Neither the heater nor carrier chip showed a significant variation in temperature across the body, and toward the edge of the substrate there was either no temperature change (for the FR4) or a negligible difference from that near the MCM (for copper). It was therefore decided that there was little benefit in selecting more nodes.

FR4 substrate: Figure 10 shows the transient thermal profile of the MCM on a FR4 substrate for a $1.2 \mathrm{~W}$ power cycle. The nodes exhibit a large initial rate of temperature change, which gradually and steadily declines as the cycle progresses and the device approaches steady state. Table 3 shows how close the substrate is to steady state at the end of the cycle. It can be seen that the substrate reaches over $95 \%$ steady state within the allocated transient cycle time, while the MCM is seen to reach $99 \%$. The trends noted in the ON cycle were echoed during the OFF cycle: an initial large temperature decrease was noted for all the nodes and the rate of temperature change declined during the later increments. Figure 11 shows the temperature difference between the heater chip and the carrier chip as a function of time. During the $\mathrm{ON}$ cycle, it can be seen that the temperature difference peaks after one second and remains near constant afterwards, reducing by only $0.1^{\circ} \mathrm{C}$ over the remainder of the cycle.

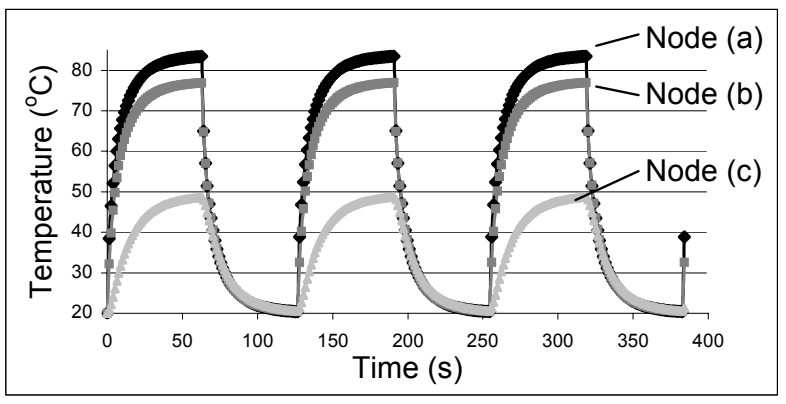

Fig. 10 Transient profile of MCM on FR4 substrate (1.2 W power input, $10 \mathrm{~m} / \mathrm{s}$ airflow).

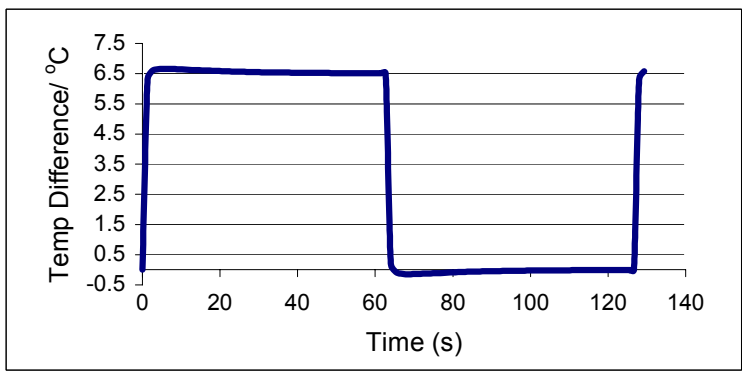

Fig. 11 Temperature difference between node (a) and node (b) in figure 10 for one complete ON/OFF cycle.

Table 3. Comparison of maximum temperature changes recorded for steady state and power cycling FE models (1.2W power input, $10 \mathrm{~m} / \mathrm{s}$ airflow).

\begin{tabular}{|l|c|c|c|}
\hline Node no & $\begin{array}{l}\text { Maximum temp } \\
\text { change in cycle } \\
\text { time }\left(\Delta \boldsymbol{T}^{\circ} \boldsymbol{C}\right)\end{array}$ & $\begin{array}{l}\text { Steady } \\
\text { state } \\
\left(\Delta \boldsymbol{T}^{\circ} \boldsymbol{C}\right)\end{array}$ & $\begin{array}{l}\text { \% steady state } \\
\text { reached }\end{array}$ \\
\hline (a) heater chip & 63.4 & 63.87 & $99 \%$ \\
\hline (b) carrier chip & 57.0 & 57.36 & $99 \%$ \\
\hline (c) substrate & 28.0 & 29.8 & $95 \%$ \\
\hline
\end{tabular}


Copper substrate: Figure 12 shows the transient thermal profile for the assembly for a power cycle level of $1.2 \mathrm{~W}$. From the graphs, it is clear that the MCM exhibited a large temperature change during the start of the $\mathrm{ON}$ cycle. However, shortly afterwards there was a sharp change in the subsequent temperature profile. It can be seen that the rate of temperature change throughout the assembly, was slower for the remainder of the cycle. A comparison with the steady state temperatures is shown in table 4 , where it can be seen that the assembly had not reached steady state at the end of the ON part of the cycle. When the heat flux is removed, the MCM experiences a rapid temperature drop until it is the same temperature as the substrate. Once the MCM has reached this temperature, it then continues to cool at a rate governed by the substrate. According to the graph, it is also apparent that no part of the assembly returns to room temperature after the power cycling has started. The transient temperature difference between the heater and carrier chips is shown in figure 13. While the temperature difference is marginally greater than that of FR4 it remains constant throughout the cycle. Also, on the OFF cycle there is no temperature difference between the heater and carrier chips after the initial rapid cool down.

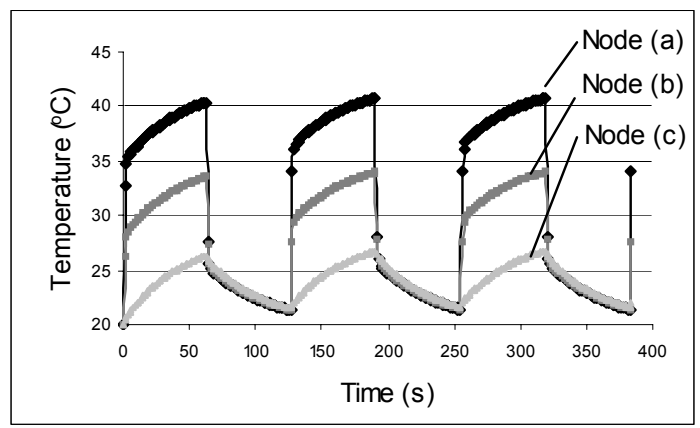

Fig. 12: Transient profile of MCM on copper substrate (1.2 $\mathrm{W}$ power input, $10 \mathrm{~m} / \mathrm{s}$ airflow).

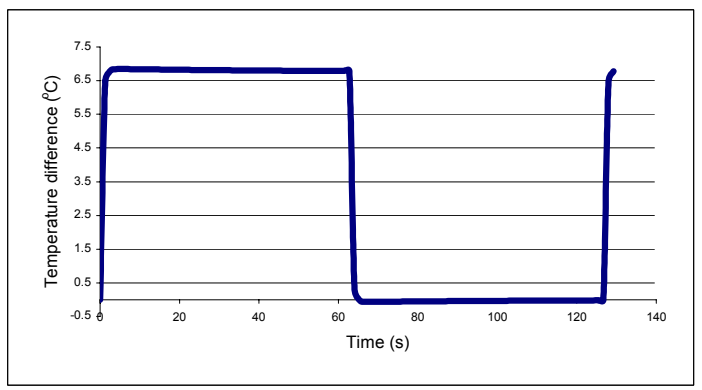

Fig. 13: Temperature difference between node (a) and node (b) in figure 12 for one complete ON/OFF cycle.

Table 4: Comparison of maximum temperature changes recorded for steady state and power cycling FE models. Copper substrate (1.2W power input, $10 \mathrm{~m} / \mathrm{s}$ airflow).

\begin{tabular}{|c|c|c|c|}
\hline Node no & $\begin{array}{l}\text { Maximum temp } \\
\text { change in cycle } \\
\text { time }\left({ }^{\circ} \mathrm{C}\right)\end{array}$ & $\begin{array}{l}\text { Steady } \\
\text { state } \\
\left(\Delta T^{\circ} \mathrm{C}\right)\end{array}$ & $\begin{array}{l}\text { \% steady } \\
\text { state } \\
\text { reached }\end{array}$ \\
\hline (a) heater chip & 20.4 & 22.17 & $91 \%$ \\
\hline (b) carrier chip & 13.6 & 15.41 & $88 \%$ \\
\hline (c) substrate & 6.3 & 8.33 & $76 \%$ \\
\hline
\end{tabular}

\section{Validation of Transient Thermal Models}

The MCM test assembly was positioned in the wind tunnel and the power levels and airflow velocities were set to match the transient power levels from the FE models (i.e. 1.2 $\mathrm{W}$ and $10 \mathrm{~m} / \mathrm{s}$ ). A timer was connected between the power supply and test assemblies such that the desired $64 \mathrm{~s}$ ON/OFF cycle was implemented. Once the power levels were set, the test vehicle was left to complete 4 cycles before any thermal data was captured. The IRISYS low-resolution camera was then used to capture the thermal data for three cycles. Using the pixel allocation shown in figure 4 , thermal data was then extracted.

FR4 substrate: An example of a thermal image from which the transient data was captured is shown in figure $14 \mathrm{a}$ together with the pixel allocation. The transient profiles of the highlighted pixels are shown in figure 14b. All the recorded parts of the assembly can be seen to initially heat up rapidly, after which the rate of temperature increase slows down towards the latter part of the cycle. Likewise, this behaviour is reciprocated on the OFF cycle. A temperature change of $60^{\circ} \mathrm{C}$ was recorded for the heater chip, while a temperature of $54^{\circ} \mathrm{C}$ was estimated for the carrier chip. These results were in good agreement with the thermal models. a)

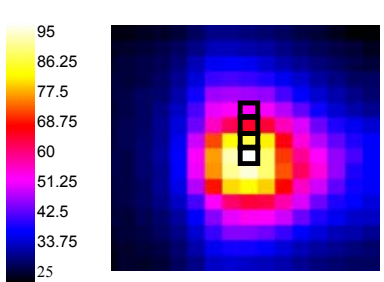

b)

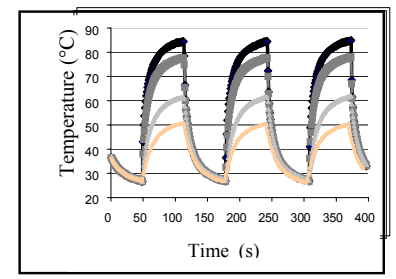

Fig.14 Power cycling of MCM on FR4 substrate (1.2W) power input, $10 \mathrm{~m} / \mathrm{s}$ airflow). a) sample thermal image, b) transient temperature profiles of the pixels shown in (a).

Copper substrate: Figure 15 shows the data obtained for the MCM on the copper substrate. An initial steep temperature rise is evident throughout the assembly, which then changes abruptly to a much gentler, slower temperature change. As with the FR4 trial, the trend is repeated in the OFF part of the cycle. Again, the experimental results showed good agreement with the general shape of the graphs from the thermal models, especially the sharp initial temperature rise upon power $\mathrm{ON}$.

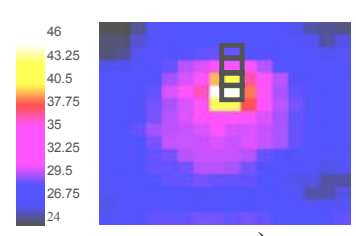

a)

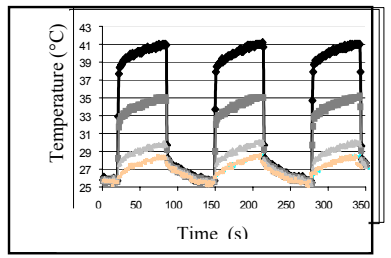

b)
Figure 15: Power cycling of MCM on copper substrate (1.2 $\mathrm{W}$ power input, $10 \mathrm{~m} / \mathrm{s}$ airflow). a) sample thermal image, b) transient temperature profiles of the pixels shown in (a). 


\section{DISCUSSION \\ Influence of Substrate Material}

Steady state: Table 5 presents the steady state temperature rises for the test vehicles utilising either FR4 or copper substrates. It can be seen that when copper was used, the final temperatures reached were significantly lower than for FR4 by a factor of three. While the FR4 substrate showed a temperature gradient as the distance from the MCM increased, the copper substrate showed an almost uniform temperature throughout. The poor conductivity of the FR4 substrate impeded heat transfer to substrate areas further away from the MCM and therefore the majority of the heat loss from the MCM was thought to be via convection directly to the air rather than through conduction into the substrate. In comparison, the copper has very good thermal conductivity and diffused the heat from the MCM throughout the substrate and provided a much larger surface area for convection heat transfer.

Table 5. Overall temperature changes from steady state analysis ( $1.2 \mathrm{~W}$ power input, $5 \mathrm{~m} / \mathrm{s}$ airflow). The same nodes were chosen from each model.

\begin{tabular}{|l|c|c|c|}
\hline Node & $\begin{array}{l}\text { FR4 } \\
\text { substrate } \\
\left(\Delta \boldsymbol{T}^{\circ} \boldsymbol{C}\right)\end{array}$ & $\begin{array}{l}\text { Copper } \\
\text { substrate } \\
\left(\Delta \boldsymbol{T}^{\circ} \boldsymbol{C}\right)\end{array}$ & $\begin{array}{l}\text { Temperature rise } \\
\text { from copper model } \\
\text { as a \% of FR4 } \\
\text { model }\end{array}$ \\
\hline (a) heater chip & 80.4 & 26.1 & $32 \%$ \\
\hline (b) carrier chip & 73.7 & 19.29 & $27 \%$ \\
\hline (c) substrate & 40.7 & 11.97 & $30 \%$ \\
\hline
\end{tabular}

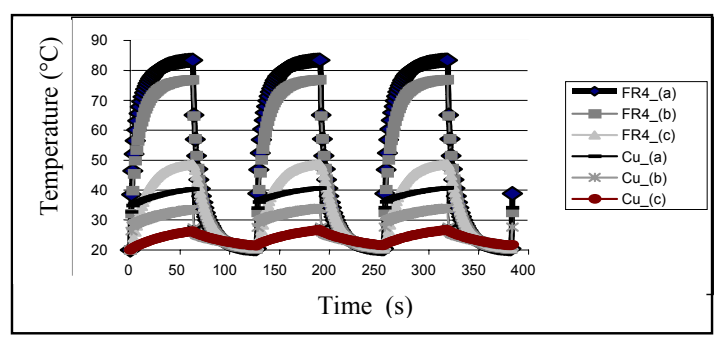

Figure 16: Comparison of the transient behaviour of the nodes for FR4 and copper substrates (power level 1.2W, airflow $10 \mathrm{~m} / \mathrm{s}$ )

Transient results: The transient thermal performance of the MCMs was strongly affected by changing the substrate properties from FR4 to copper. For comparison, the transient profile for the test vehicles on FR4 and copper are summarised in figure 16 . With copper as a substrate the maximum temperature reached was reduced, in line with the steady state results. For both materials, the temperature of the components showed an initial steep gradient. The slope of this initial rise is related to the thermal mass of the die and the thermal resistance between it and the carrier chip. However, for FR4 there was a gradual reduction in the rate of temperature change, as opposed to the sharp change exhibited when a copper base was used. In addition, despite reaching lower maximum temperatures, it was apparent that the MCM on copper substrate never returned to its initial temperature, which was attributed to the high conductivity of the copper and the large substrate thermal mass. Overall, the copper substrate was observed to heat up and cool at a much lower rate than the MCM and was ultimately found to govern the minimum temperature the MCM would reach

\section{CONCLUSION}

It has been shown that with careful consideration of the relevant modeling parameters, a power cycle simulation can be performed utilising FE software. In this work, substantial care was taken in accurately defining the convection heat transfer coefficients, which are critical to obtaining the maximum temperature reached, the transient profile and time taken to reach steady state. Models were validated by comparison of the results with MCM assemblies that were observed using thermal imaging cameras.

It was found that while the temperature difference between the heater and the carrier chips were shown to be very similar regardless of the substrate, the MCMs on copper substrates reached a much lower peak temperature than those on FR4 for a given power level.

\section{REFERENCES}

[1] J.H. Lau (ed), Low Cost Flip Chip Technologies, (Chapter 1), McGraw-Hill, New York, 1999.

[2] G. Grossmann and L. Weber "Metallurgical Considerations for Accelerated Testing of Soft Solder Joints" IEEE Trans. Comp. Pack. and Man. Tech. Part C Volume 20 No 3, July 1997, pp 213-8.

[3] J. H. Pang, et al, "Thermal Cycling Aging Effects on Microstructual and Mechanical Properties of a Single PBGA Solder Joint Specimen" IEEE Trans. Comp. Pack. Tech. Volume 24 No 1, March 2001, pp 10-15.

[4] A.D. Trigg and A.R. Corless, "Thermal Performance and Reliability Aspects of Silicon Hybrid Multi-Chip Modules" Proceedings of the $40^{\text {th }}$ IEEE CPMT Electronic Components and Technology Conference, Las Vegas, 1990, pp 592-9.

[5] P. Towashiraporn, et al, "Predictive Reliability Models through Validated Correlation between Power Cycling and Thermal Cycling Accelerated Life Tests" Soldering and Surface Mount Technology, Vol, 14 Issue 3, 2002, pp 51-60. [6] B. Sur and I. Turlik, "Power Cycling and Stress Variation in a Multi-Chip Module" IEEE Transactions on Components Packaging and Manufacturing Technology part B Volume 10 no 2, May 1995, pp 388-395.

[7] J. Lenkkeri et al. "Rapid Power Cycling of Flip Chip and CSP Components on Ceramic Substrate" Microelectronics Reliability 41, Vol, 41 Issue 5, 2001, pp 661-8.

[8] D. A. Hutt, et al, "A Maskless Low-Cost Multi-Chip Module Assembly Process" Advances in Electronic Packaging (Proceedings of the InterPACK99 conference) Hawaii, ASME EEP Volume 26-2, 1999, pages 1705-11.

[9] F. Sarvar, et al , "IGBT Package Design for High Power Aircraft Electronic Systems" Journal of Electronic Packaging ASME, Vol 123 No. 4, 2001, pp 338-43

[10] F. Sarvar et al., "PCB glass-fibre Laminates: Thermal Conductivity Measurements and their effect on simulation" AIME Journal of Electronic Materials, Vol. 19 No 20, 1990, pp 1345-50

[11] K.D. Hagen, Heat transfer with applications, Prentice Hall, London, 1998 